\title{
GIS BASED ANALYSIS OF FOREST SITE PREPARATION
}

\author{
Jānis Ivanovs, Irina Sietiṇa \\ Latvian State Forest Research Institute 'Silava' \\ janis.ivanovs@silava.lv
}

\begin{abstract}
The aim of this study is to improve the practice of mechanical forest site preparation (FSP) by identifying typical characteristics of FSP, including the direction of FSP machinery, manoeuvre count depending on configuration of parcel and forest type and width of manoeuvre track; to evaluate the productivity depending on different forest growing conditions; to create schemes of technological corridors for commercial thinning; to improve scheme of FSP according to the scheme of technical corridors for commercial thinning and to evaluate changes in the count of manoeuvres and total distance travelled.

In this study, we have developed methods to evaluate the quality of FSP. Methods used in this study include GIS analysis of vector data from FSP machinery tracking devices and LiDAR (Light detecting and ranging) data analysis for terrain information. Study shows that there is a significant difference in productivity when the machinery of FSP is driving in different angles to the longitudinal axis of parcel. Reduced productivity is justified by prioritizing topography of the forest floor. Slope is a decisive factor in the ground water movement and should be considered in FSP planning. Study shows that the developed method could be implemented in practice of forest management in $41 \%$ of sampled forest stands.
\end{abstract}

Key words: Forest site preparation, forest management, groundwater, GIS, DEM.

\section{Introduction}

Mechanical FSP is widely used to provide prompt and successful regeneration of harvested forest lands (Schmidtl \& Macdonald, 1996). FSP may include changes of growth conditions in order to improve microsites for seeding. The manipulations may include such operations as changing soil moisture properties, increasing the amount of available solar radiation, changing soil temperature, increasing soil nutrient availability, reducing compaction of soil and competing vegetation control (Löf et al., 2012). FSP is important for tree establishment, early survival and growth (Hawkins, Steele, \& Letchford, 2006).

FSP can lead to soil disturbance and can result in loss of carbon from soil (Jandl et al., 2007). Carbon loss may be significant in forest sites, which are located on slopes, especially in down-slope plowing conditions (Edeso, Merino, \& Gonzalez, 1999). In sites without protection areas with trees and vegetation, the nutrients and organic matter may affect water quality in adjacent streams (Ahtiainen, 1992).

Heavy forest machinery may lead to disturbances of the groundwater flows. While soil compaction has little effect on ground water movement, rutting may lead to increased water table and dramatically restricted subsurface water flow (Aust et al., 1998). In order to characterise the groundwater movement in local areas, nests of piezometers and wells can be used, but on regional scale it may become expensive, impractical and intrusive (Whiteman et al., 2012). On regional scale for modelling of groundwater movement and discharge, precise geological data (Levine \& Salvucci, 1999) or thermal imagery could be used (Sass et al., 2014).

The aim of this study is to improve the practice of mechanical FSP in order to minimize the tree damage by commercial thinning. The objectives of this study are to identify common schemes of FSP; to calculate theoretical productivity of FSP at different angles to the longitudinal axis of parcel; to analyse FSP depending on slope and to develop improved planning scheme of FSP.

\section{Materials and Methods}

Joint Stock Company 'Latvia's State Forests' database of GPS data from FSP machinery is used in this study. 671 forest stands are used in analysis; the included forest types are: Myrtillosa, Hylocomiosa, Oxalidosa, Mercurialosa mel. and Myrtillosa mel. LiDAR data for topographical analysis of FSP is obtained from Latvian Geospatial Information Agency and the average point cloud density is 4 points $\mathrm{m}^{-2}$.

FSP machinery direction analysis is based on trigonometrical principles, where productivity is calculated using different directions and longitudinal axis of parcels. Configuration of forest stands are from simple rectangles to complex shapes. Because of the complexity of polygons, we use simple geometrical values like length and width of the minimum bounding box of a parcel. We assume that for polygon to be outstretched, the division of width and length should be below 0.7 or 0.6 . In this study we use both values (Figure 1).

Complexity of polygons is expressed as empty space in the minimum bounding box around the shape. We assume that forest stand is complex if empty space in the bounding box is more than $30 \%$ and $40 \%$. In this study we use both values (Figure 2).

In order to calculate the direction of forest site preparing machinery, GPS data is generalized. The main direction of forest stand crossing is calculated by azimuth ( $\alpha$ ) and length (l) of each crossing as 
Legend

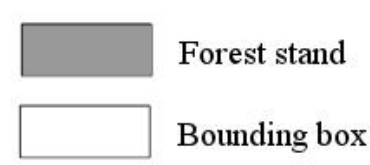
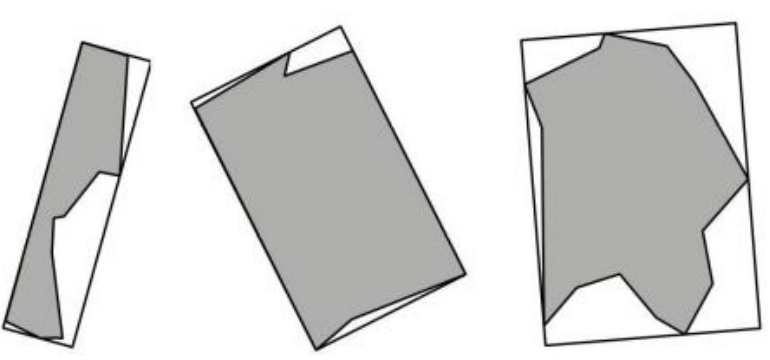

Figure 1. Example of outstretched forest stands.

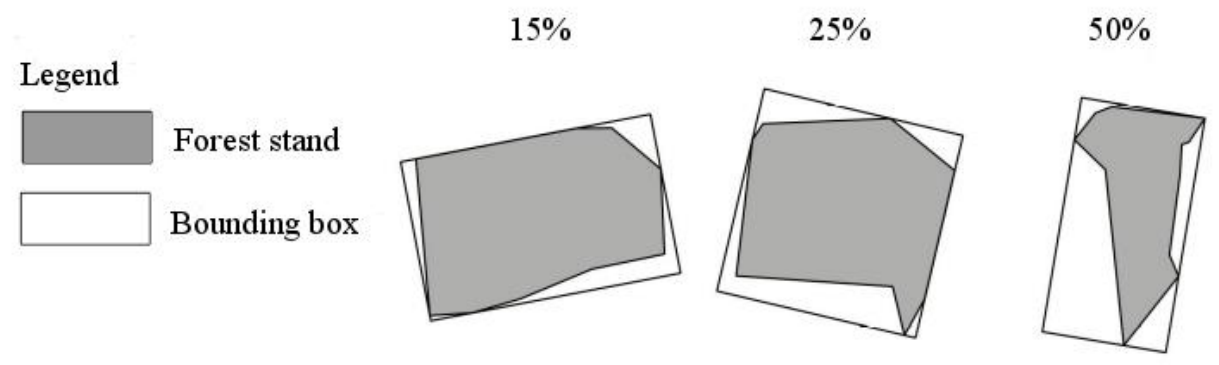

Figure 2. Example of complexity of forest stands.

weighted average with the maximum value of $180^{\circ}$ (Formula 1).

$$
a=\frac{a_{1} * l_{1}+a_{2} * l_{2} \ldots a_{n} * l_{n}}{\sum l}
$$

In order to analyse longitudinal axis of forest stand parcel $\left(\alpha_{\mathrm{n}}\right)$ relation with direction of FSP machinery $(\alpha)$, we use the following formula (Formula 2):

$$
\Delta a=a-a_{n}
$$

The value of relation may be in range from $0^{\circ}$ to $90^{\circ}$. We analyse results in three categories with ranges $0^{\circ} \ldots 25^{\circ}, 0^{\circ} \ldots 35^{\circ}$ and $0^{\circ} \ldots 40^{\circ}$. Boundary values of forest stand shape (ratio between shape width and length, complexity and ratio between longitudinal axis of forest stand parcel and direction of FSP machinery) are merged into the variable (40-40p-07; 40-40p-06; etc). The correlation between direction and longitudinal axis is stronger for the smallest values. In order to calculate the productivity of FSP, we use data about trajectory of FSP machinery, width of prepared zone and driving speed. The average width of the prepared zone is $7.5 \mathrm{~m}$ and the average driving speed is assumed to be $1 \mathrm{~km} \mathrm{~h}^{-1}$.

To calculate the distance of FSP machinery turning manoeuvres in different forest types, GPS tracked trajectories are manually split into separate segments (Figure 3). The average turning distance is calculated for each forest type.

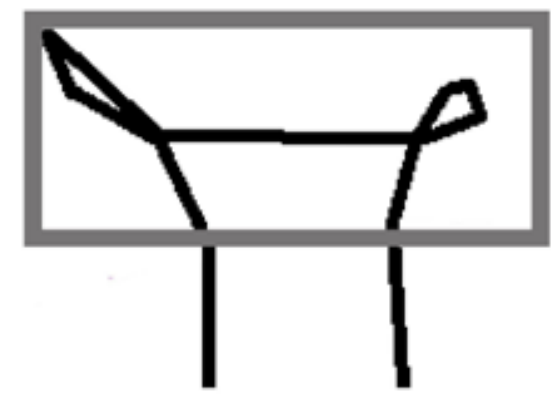

Figure 3. Turning manoeuvre of FSP machinery.

The terrain in all forest sites is classified in 4 aspect classes:

- North - south $\left(0^{\circ} \ldots 2.5^{\circ} ; 337.5^{\circ} \ldots 0^{\circ}\right.$; $\left.157.5^{\circ} \ldots 202.5^{\circ}\right)$

- Northeast $\quad-$ southwest $\quad\left(22.5^{\circ} \ldots 67.5^{\circ}\right.$; $\left.202.5^{\circ} \ldots 247.5^{\circ}\right)$;

- Southeast - northwest $\left(112.5^{\circ} \ldots 157.5^{\circ}\right.$; $\left.292.5^{\circ} \ldots 337.5^{\circ}\right)$

- West - east $\left(67.5^{\circ} \ldots 112.5^{\circ} ; 247.5^{\circ} \ldots 292.5^{\circ}\right)$.

Classes are combined for opposite directions because longitudinal axis of forest site is calculated in $180^{\circ}$ and optimal trajectory of FSP machinery is the same on opposite slopes. To avoid groundwater movement disturbance, it is advisable for harvesting machinery to move in parallel to a slope gradient. In order to avoid soil erosion, FSP machinery should be driven perpendicular to a slope gradient.

In most cases, in the studied area, the terrain has no single main aspect, and local depressions 
are detected. Groundwater and surface water are concentrating in depressions without run-off and it is advisable for heavy forest machinery to avoid such places. In order to navigate through depressions, causing as little damage to soil as possible, complex groundwater movement calculations are needed. The amount of water in depressions depends on variables, such as soil type, texture of sediments, intensity of precipitation, transpiration, evapotranspiration etc. Accurate data for these parameters in the studied area are not available.

We assume that groundwater flow has the same direction as the aspect of the slope. In forest stands with different aspects and local depressions, empirical data is needed to evaluate characteristics of groundwater flow. Local depressions in the studied area are detected using LiDAR data, which are processed in QGIS software using Fill sinks algorithm.

\section{Results and Discussion}

Analysis of FSP and shape of a forest stand

Theoretical total distance of straight segments in different forest stand configurations is calculated using trigonometrical formulas and characteristics of simple figures. Calculations are made for 1 ha large polygons with different FSP machinery trajectory angles to the longitudinal axis and different coefficients of complexity and outstretchiness of a forest stand (Figure 4).

Results show that the total travelling distance is the shortest when FSP machinery is driven in the same direction as longitudinal axis of forest stand. The total travelled distance is growing till the coefficient of outstretchiness is about 0.7 . After that there is no significant difference for driving parallel or perpendicular to the longitudinal axis. $76 \%$ of the studied forest sites are within coefficient values below 0.7 .

The longest travelling distance of FSP machinery for whatever value of outstretchiness coefficient is at $45^{\circ}$ angle to the longitudinal axis of the forest stand. The total distance decreases when the shape of the polygon is becoming more regular. Figure 4 explains why operators of FSP machinery tend to drive in parallel to the longitudinal axis of a forest stand.

There is a strong correlation between the total area of forest stand and total distance travelled $(r=0.97)$, which is logical. There is no correlation between the forest stand area and density of trajectories of FSP machinery.

A summary of forest stand complexity in the studied area is shown in Table 1 . Complexity of a

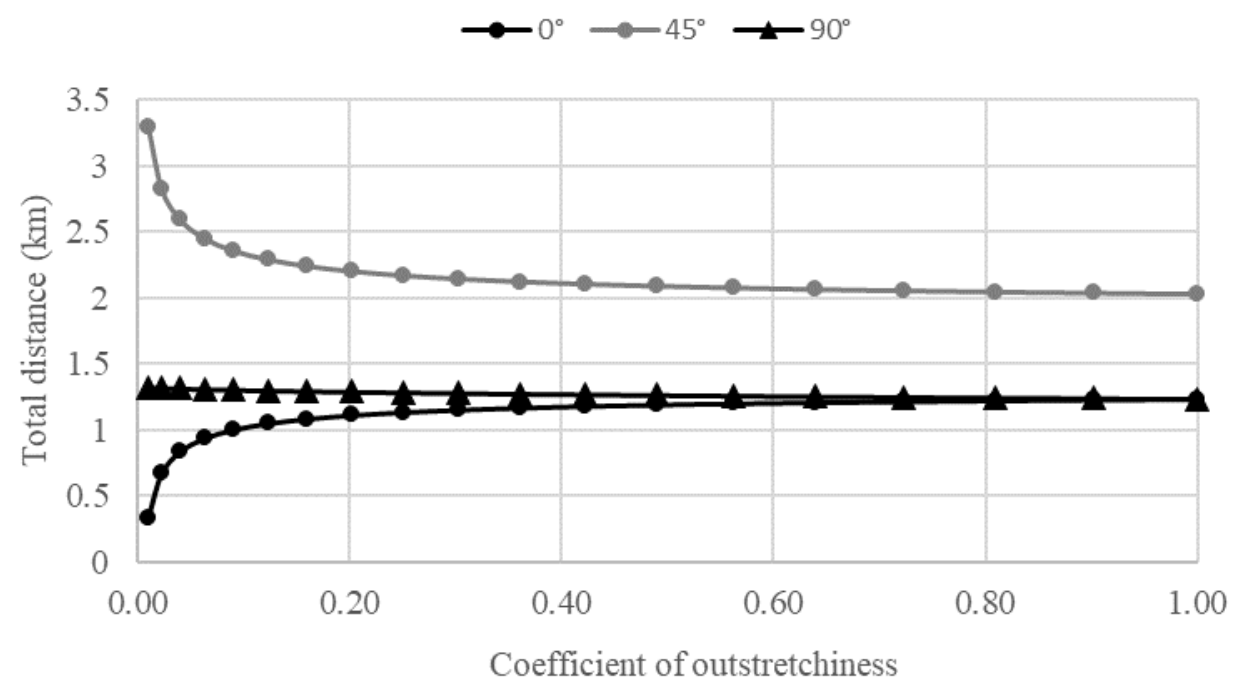

Figure 4. Total distance travelled in straight segments by different angles to longitudinal axis of forest stand.

\section{Complexity of forest stands in the studied area}

Table 1

\begin{tabular}{|c|c|c|}
\hline \multirow{2}{*}{ Outstretchiness } & Complexity less than $30 \%$ & Complexity less than $40 \%$ \\
\hline \multirow{2}{*}{$>0.6$} & 287 ha & 466 ha \\
\cline { 2 - 3 } & $27 \%$ & $44 \%$ \\
\hline \multirow{2}{*}{$>0.7$} & 322 ha & 546 ha \\
\cline { 2 - 3 } & $30 \%$ & $51 \%$ \\
\hline
\end{tabular}




\section{Characteristics of FSP machinery turning point}

\begin{tabular}{|l|c|c|c|c|c|}
\hline \multicolumn{1}{|c|}{ Forest type } & $\begin{array}{c}\text { Average turning } \\
\text { distance }(\mathrm{m})\end{array}$ & $\begin{array}{c}\text { Average turning } \\
\text { count }\left(\text { count ha }{ }^{-1}\right)\end{array}$ & $\begin{array}{c}\text { Total turning } \\
\text { distance }\left(\mathrm{km} \mathrm{ha}^{-1}\right)\end{array}$ & Total area (ha) & $\begin{array}{c}\text { Forest stand } \\
\text { count }\end{array}$ \\
\hline Myrtillosa & 32 & 20 & 0.63 & 15.71 & 12 \\
\hline Oxalidosa & 29 & 16 & 0.47 & 70.09 & 33 \\
\hline Hylocomiosa & 27 & 17 & 0.46 & 16.06 & 11 \\
\hline Myrtillosa mel. & 27 & 19 & 0.52 & 22.37 & 15 \\
\hline Mercurialosa mel. & 32 & 12 & 0.37 & 7.82 & 4 \\
\hline \multicolumn{1}{|c|}{ Average } & 28 & 17 & 0.48 & 132.05 & 75 \\
\hline
\end{tabular}

forest stand affects the travelling distance of the forest site preparing machinery. More complex shapes tend to increase travelling distance and lower the productivity.

The average turning distance on the edges of forest stands is shown in Table 2. Turning distance characteristics depend mostly on the forest type. The average turning distance is $28 \mathrm{~m}$ and average total turning distance on 1 ha is $480 \mathrm{~m}$. The biggest turning distance on average is in Myrtillosa forest type, because of a more complex pattern of soil scarification, most probably due to wet spots, which has to be bypassed. Lower ground bearing capacity means that the operator of FSP machinery should be more careful to avoid soil damage (rutting, compaction etc.).

Productivity of FSP is calculated theoretically and empirically using GPS data. Empirically calculated data shows that for 1 ha FSP 2 hours and 30 minutes are needed. Theoretical time for 1 ha preparation, if the operator is driving at $1 \mathrm{~km} \mathrm{~h}^{-1}$ is 2 hours and 38 minutes. Theoretical time for 1 ha of FSP in $45^{\circ}$ angle is 2 hours and 46 minutes.

\section{Analysis of FSP and terrain}

For analysis of FSP in the context of terrain, we use forest stands where FSP machinery trajectories are close to the angle of the longitudinal axis of polygon, with regular shape and are relatively outstretched. In total, 105 forest stands are selected with a total area of
160.82 ha. LiDAR elevation data is available for all selected areas.

In order to evaluate the possibility of terrain data being used in heavy machinery movement planning in forest stands, aspect data is sorted in 4 classes in growing succession. We assume that a particular aspect class is dominant in a forest stand if it covers more than $30 \%$ of area. There is at least one dominant aspect class in $43.8 \%$ of forest stands and no areas with only one aspect class in the studied area (Table 3).

Terrain in the studied area is relatively flat. Slope in $81.5 \%$ of the studied area is within $0-3^{\circ}$ (Table 4 ). Only in $15 \%$ of the studied area the slope is significant. Because of high vulnerability to the disturbances in groundwater movement in flat areas, the planning of heavy forest machinery movement across forest stands is increasingly valuable. Disturbances in the groundwater flow may lead to bogging process. Small standard deviation means that flat areas are with a low variety.

Local depressions are analysed to find out how large areas within forest stands are exposed to excessive water accumulation. Only in $18.1 \%$ of forest stands depressions take less than $10 \%$ of area (Table 5). In largest proportion of forest stands, depressions take between 10 and $50 \%$ of the total forest stand area. In $7.6 \%$ of studied forest stands depression area takes more than $50 \%$.

\section{Average proportion of max and min aspect class}

\begin{tabular}{|l|c|c|c|c|}
\hline \multicolumn{1}{|c|}{ Forest stand area } & $\begin{array}{c}\text { Average maximal } \\
\text { value }\end{array}$ & $\begin{array}{c}\text { Average } 2^{\text {nd }} \text { maximal } \\
\text { value }\end{array}$ & $\begin{array}{c}\text { Average } 3^{\text {rd }} \text { maximal } \\
\text { value }\end{array}$ & $\begin{array}{c}\text { Average minimal } \\
\text { value }\end{array}$ \\
\hline Average & $31.0 \%$ & $25.6 \%$ & $22.82 \%$ & $20.5 \%$ \\
\hline Minimal & $25.5 \%$ & $16.4 \%$ & $9.0 \%$ & - \\
\hline Maximal & $55.1 \%$ & $34.0 \%$ & $25.9 \%$ & $24.4 \%$ \\
\hline Stdev & $5.9 \%$ & $2.4 \%$ & $2.6 \%$ & $3.8 \%$ \\
\hline
\end{tabular}


Area of depressions within forest stands

\begin{tabular}{|l|l|}
\hline \multicolumn{1}{|c|}{ Area of depressions $\%$} & \multicolumn{1}{c|}{ Forest stands \% } \\
\hline Less than 10 & 18.1 \\
\hline $10 \ldots 20$ & 29.5 \\
\hline $20 \ldots 30$ & 24.8 \\
\hline $30 \ldots 40$ & 20 \\
\hline More than 50 & 7.6 \\
\hline
\end{tabular}

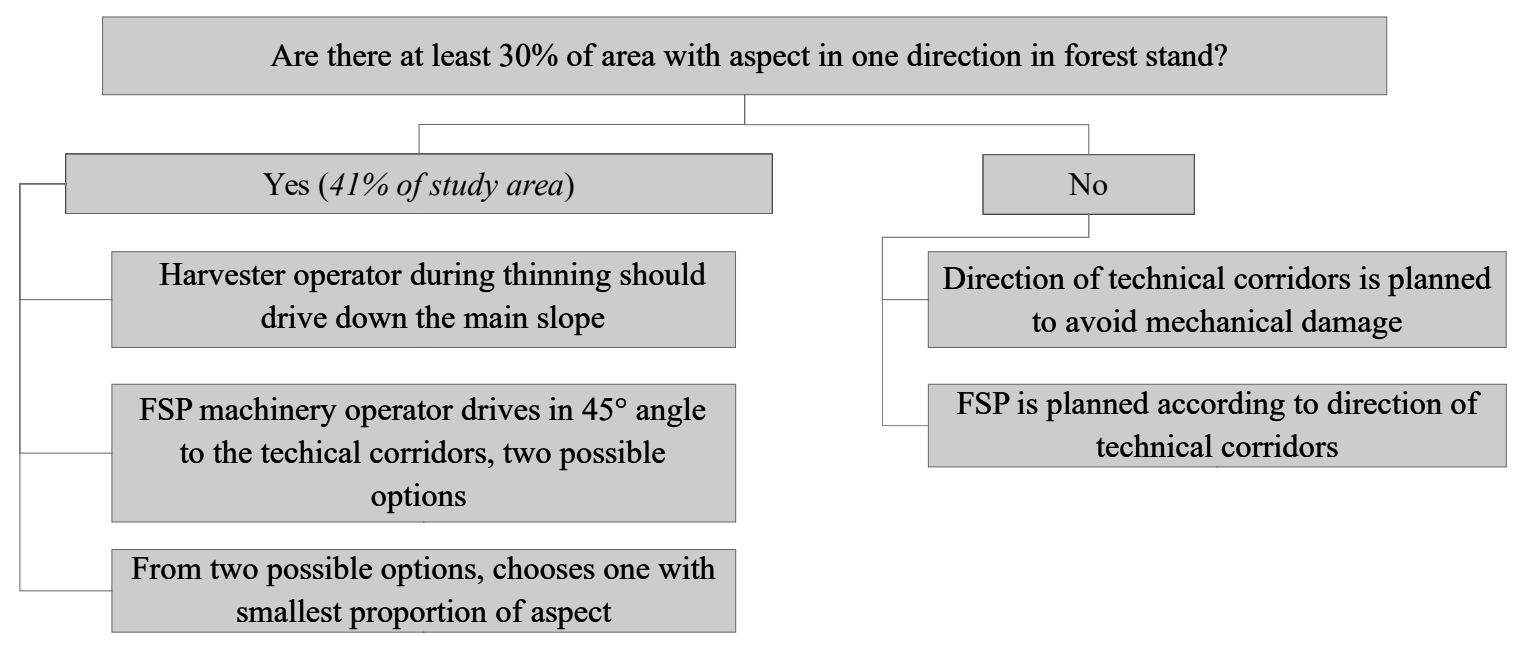

Figure 5. Decision support tree for FSP planning.

Drainage basins indicate complexity of terrain and groundwater movement in the area. $38 \%$ of forest stands are within one drainage basin, which means that groundwater drains in one direction. Forest stands with one drainage basin and with one dominant aspect in the study area are just $12.3 \%$. In those forest stands, the planning of driving pattern of the heavy forest machinery theoretically is simple. $62 \%$ of forest stands in the study area are located within two or more drainage basins.

Results of this study show that data about forest stand configuration and terrain can be used in FSP planning. Summary of used analysis methods has resulted in recommendations for FSP planning (Figure 5). According to the proposed decision, support tree a stand is first evaluated for possibilities to optimize soil scarification so that groundwater flow is not affected and, if it is not possible, the scarification direction is subordinated to optimized strip-road pattern.

\section{Conclusions}

1. FSP usually occurs in the same direction as the longitudinal axis of a forest stand parcel without taking into account the terrain. The travelled distance of FSP and consumed time can be modelled in regularly shaped forest stands. Forest type does not influence the total travelled distance of FSP machinery.

2. Direction of FSP machinery to the longitudinal axis of a forest stand has significant influence on productivity and, by changing direction, the costs of FSP may increase. To accurately calculate the additional costs, empirical data about FSP machinery speed and fuel consumption is needed.

3. Results of this study show that in $41 \%$ of the studied forest stands it is possible to minimize the tree damage by implementing the developed methodology.

\section{Acknowledgements}

The study was implemented within the scope of the JSC 'Latvia's state forests' funded research project 'Research program on forest biofuel and mechanization of forest operations' (agreement No 5-5.9_003v_101_16_47). 


\section{References}

1. Ahtiainen, M. (1992). The effects of forest clear-cutting and scarification on the water quality of small brooks. Hydrobiologia, 243 - 244(1), 465 - 473. DOI: 10.1007/BF00007064.

2. Aust, W.M., Burger, J.A., Carter, E.A., Preston, D.P., \& Patterson, S.C. (1998). Visually Determined Soil Disturbance Classes Used as Indices of Forest Harvesting Disturbance. Southern Journal of Applied Forestry, 22(4), $245-250$.

3. Edeso, J., Merino, A., \& Gonzalez, M. (1999). Soil erosion under different harvesting managements in steep forestlands from northern Spain. Land Degradation \& Development, 10, $79-88$.

4. Hawkins, C.B., Steele, T.W., \& Letchford, T. (2006). The economics of site preparation and the impacts of current forest policy: evidence from central British Columbia. Canadian Journal of Forest Research, 36(2), 482 - 494. DOI: 10.1139/x05-262.

5. Jandl, R., Lindner, M., Vesterdal, L., Bauwens, B., Baritz, R., Hagedorn, F., ... Byrne, K.A. (2007). How strongly can forest management influence soil carbon sequestration?, 137, 253 - 268. DOI: 10.1016/j. geoderma.2006.09.003.

6. Levine, J.B., \& Salvucci, G.D. (1999). Equilibrium analysis of groundwater-vadose zone interactions and the resulting spatial distribution of hydrologic fluxes across a Canadian Prairie. Water Resources Research, 35(5), 1369 - 1383. DOI: 10.1029/1999WR900018.

7. Löf, M., Dey, D.C., Navarro, R.M., \& Jacobs, D.F. (2012). Mechanical site preparation for forest restoration. New Forests, 43, 825 - 848. DOI: 10.1007/s11056-012-9332-x.

8. Sass, G.Z., Creed, I.F., Riddell, J., \& Bayley, S.E. (2014). Regional-scale mapping of groundwater discharge zones using thermal satellite imagery. Hydrological Processes, 28, 5662 - 5673. DOI: 10.1002/hyp.10068.

9. Schmidtl, M.G., \& Macdonald, S.E. (1996). lmpacts of harvesting and mechanical site preparation bn soil chemical pioperties of mixed-wood boreal forest sites in Alberta. Canadian Journal of Soil Science, 76, $531-540$.

10. Whiteman, M.I., Seymour, K.J., Van Wonderen, J.J., Maginness, C.H., Hulme, P.J., Grout, M.W., \& Farrell, R.P. (2012). Start, development and status of the regulator-led national groundwater resources modelling programme in England and Wales. Geological Society, London, Special Publications, 364(1), 19 - 37. DOI: $10.1144 /$ SP364.3. 